\title{
Atributos e dimensões de qualidade da informação nas Ciências Contábeis e na Ciência da Informação: um estudo comparativo
}

\section{Nelma T. Zubek Valente}

Doutora pelo Programa de Pós-Graduação em
Ciência da Informação da Escola de
Comunicações e Artes da Universidade de São
Paulo(PPGCI-ECA/USP). Docente e pesquisadora
do Departamento de Contabilidade da
Universidade Estadual de Ponta Grossa
(UEPG/PR)

Asa Fujino

\begin{abstract}
Mestre e Doutora em Ciências da Comunicação pela Escola de Comunicações e Artes da USP. Docente e pesquisadora do Departamento de Biblioteconomia e Documentação da Escola de Comunicações e Artes da Universidade de São Paulo
\end{abstract}

http://dx.doi.org/10.1590/1981-5344/2530

Apresenta análise comparativa entre atributos de qualidade da informação adotados no campo das Ciências Contábeis (CC) e da Ciência da Informação (CI). Parte-se do pressuposto que o conceito de qualidade da informação é fundamental para as duas áreas de conhecimento, mas é um conceito difuso e depende da base epistemológica utilizada para defini-lo. O objetivo foi identificar semelhanças e/ou diferenças entre os pressupostos adotados para qualificar a informação nos dois campos como base para compreensão das relações entre a informação e seu potencial usuário. Além da inexistência de consenso quanto ao conceito de qualidade da informação, os resultados mostram que também não existe consenso em relação às categorias, dimensões e atributos de qualidade utilizados para qualificar a informação na CI. Tais resultados sugerem que esforços podem ser feitos na CI para buscar a consolidação de um framework geral que possa servir como referência na definição e análise da qualidade da informação nessa área do conhecimento. $E$, que, iniciativas podem ser tomadas no campo das CC visando a revisão de seu framework de qualidade da informação para incorporar em sua estrutura 
conceitual atributos de qualidade da informação considerados pela $C I$ que podem contribuir para a melhoria da qualidade das informações contábeis.

Palavras-chave: Qualidade da Informação; Atributos e dimensões de qualidade; Ciências Contábeis; Ciência da Informação.

\section{Attributes and dimensions of information quality in Accounting Sciences and Information Science: a comparative analysis}

This paper shows the results of comparative analysis between the attributes of quality of information used in the field of Accounting Sciences (AS) and Information Science (IS.) Its assumed that the concept of quality of information is fundamental for these two areas of knowledge, but it's a diffuse concept and it depends on the epistemological basis used to define it. The purpose was to identify similarities and / or differences between the assumptions adopted to describe the information in the two fields as a basis for understanding the relationship between information and its potential user. The results have shown not only the absence of consensus regarding the concept of information quality, but also that there is no consensus about the categories, dimensions and quality attributes used to qualify the information in the IS field. Such results suggest that efforts can be made in the Information Science field to pursue the consolidation of a general framework that could serve as a reference in the definition and analysis of information quality in this area of knowledge. And these results also suggest that initiatives can be taken in the field of Accounting in order to review its framework for information quality to incorporate into its conceptual framework, attributes of information quality considered by the IS, which can contribute to improve the quality of accounting information. 
Keywords: Information Quality; Dimensions and attributes of quality; Accounting Sciences; Information Science.

Recebido em 03.09.2015 Aceito em 17.04.2016

\section{Introdução}

A qualidade da informação é um tema abordado por diferentes campos do conhecimento, mas de difícil consenso, em razão do alto grau de subjetividade envolvido no conceito (PAIM; NEHMY; GUIMARÃ̃ES, 1996; NEHMY; PAIM, 1998). Por outro lado, o avanço dos estudos sobre o tema tem resultado em sugestões de diferentes atributos, dimensões, classes, categorias ou características para atribuir qualidade à informação. $\mathrm{E}$, mesmo nos casos em que se observam similaridades, tais atributos são apresentados de forma dispersa, sem definições claras e sem qualquer agrupamento mais sistemático. (EPPLER; WITTIG, 2000).

Nas Ciências Contábeis, a qualidade da informação é respaldada por um conjunto de parâmetros denominado "Características Qualitativas da Informação Contábil-Financeira Útil", pertencentes à "Estrutura Conceitual para Elaboração e Divulgação de Relatório Contábil-Financeiro" estabelecida como uma das Normas Brasileiras de Contabilidade de cunho técnico e de orientação geral. A referida norma, denominada Norma Brasileira de Contabilidade Técnica Geral - NBC TG teve a sua redação alterada pela Resolução n. 1.374, de 2011, do Conselho Federal de Contabilidade (CFC) em 16 de dezembro de 2011 para ajustar-se ao Pronunciamento Conceitual Básico (R1) do Comitê de Pronunciamentos Contábeis (CPC) (CPC, 2011; CFC, 2011). Há um framework com atributos e características de qualidade da informação definidos e estabelecidos pelos órgãos normatizadores da contabilidade para serem observados pelos produtores quando da elaboração e divulgação das demonstrações contábeis para usuários externos visando a qualidade das informações geradas e divulgadas pela contabilidade. (CPC, 2011; CFC, 2011). Não há, contudo garantia que tais atributos sejam suficientes para conferir qualidade à informação contábil como esperado pelos órgãos que os estabeleceram. Assim, elaborou-se o presente estudo com vistas a realizar uma análise comparativa entre os atributos pertencentes às "Características Qualitativas da Informação Contábil-Financeira Útil" presentes na nova Estrutura Conceitual da Contabilidade, vigente no Brasil a partir de 2011, e os atributos de qualidade da informação que subsidiam os estudos da Ciência da Informação, para identificar similaridades e/ou diferenças entre os critérios adotados para qualificar a informação nos dois campos do conhecimento. Os resultados dessa análise podem contribuir para subsidiar estudos sobre a qualidade da informação nas duas áreas do conhecimento visto que ambas tem a informação como elemento essencial e concebida para atender potenciais usuários. 


\section{Método da pesquisa}

A pesquisa, de natureza qualitativa desenvolveu-se por meio de estudo comparativo entre os atributos, dimensões e categorias utilizados para qualificar a informação e determinar a qualidade da informação na Ciência da Informação e os atributos componentes das "Características Qualitativas da Informação Contábil-Financeira Útil" pertencentes à "Estrutura Conceitual para a Elaboração e Divulgação de Relatório Contábil-Financeiro" vigente no Brasil a partir de 2011 estabelecida como uma das Normas Brasileiras de Contabilidade de cunho técnico e de orientação geral. Originado de um dos capítulos de tese de doutorado tratando da qualidade da informação contábil na perspectiva da Ciência da Informação (Valente, 2014), o presente estudo avança em relação a estudo anterior realizado sobre o tema (VALENTE; FUJINO, 2012) no qual se analisaram os atributos de qualidade da informação contábil contidos na Estrutural Conceitual da contabilidade vigente até 2010.

O embasamento do estudo está suportado na literatura da Ciência da Informação em âmbito nacional e das Ciências Contábeis, sobretudo, nos fundamentos e princípios da NBC TG Estrutura Conceitual da Contabilidade em seus aspectos legais e normativos. (CFC, 2011). O corpus de análise no campo da Ciência da Informação foi constituído pelos estudos nacionais sobre qualidade da informação recuperados da Base de Dados Referencial de Artigos de Periódicos em Ciência da Informação (BRAPCI), período 1996 a 2012. Para o levantamento das fontes realizouse inicialmente a busca por palavras-chave "qualidade da informação" e obteve-se somente 13 (treze) artigos. Assim, optou-se por fazer a busca usando-se as palavras-chave qualidade da informação sem aspas, chegando-se a um total de 56 (cinquenta e seis) trabalhos. Foram analisados os resumos de cada um desses artigos e observou-se que muitos deles, embora tratassem do tema qualidade, não focavam diretamente o tema qualidade da informação objeto deste estudo. Assim, chegou-se a 16 (dezesseis) artigos focando especificamente o tema qualidade da informação. Acrescentou-se também a esse corpus de análise uma dissertação de Mestrado (AROUCK, 2011) por considerar-se sua relevância e total pertinência para este estudo, uma vez que o autor realizou uma extensa revisão de literatura sobre o tema em questão tratando justamente sobre os atributos de qualidade da informação. De forma que o corpus de análise do estudo ficou composto por 16 (dezesseis) artigos da base BRAPCI e mais uma Dissertação de Mestrado em Ciência da Informação defendida em 2011, a saber: Greef e Freitas (2012), Arouck (2001; 2011), Assis e Moura (2012), Amaral e Sousa (2011), De Sordi e Meireles (2009; 2011), Abib (2010), Calazans e Costa (2009), De Sordi (2009), Albuquerque, Bastos e Lino (2009), Calazans (2008), De Sordi, Meireles e Grijo (2008), Oleto (2006), Lopes (2004), Nehmy e Paim (1998), Paim, Nehmy e Guimarães (1996). O Quadro 1 a seguir, mostra uma síntese do corpus de análise do estudo identificando os fundamentos teóricos que embasam os estudos sobre qualidade da 
informação no campo da Ciência da Informação, especialmente os que tratam especificamente de atributos e dimensões de qualidade da informação.

\section{Quadro 1 - Fundamentos teóricos que embasam os estudos} nacionais sobre qualidade da informação no campo da $\mathrm{Cl}$

\begin{tabular}{|c|c|}
\hline Autores / Ano & $\begin{array}{l}\text { Fundamento utilizado para análise da qualidade da } \\
\text { informação }\end{array}$ \\
\hline AROUCK (2011) & $\begin{array}{l}\text { Dimensões e atributos de qualidade da informação propostos com base em revisão } \\
\text { da literatura em língua inglesa. }\end{array}$ \\
\hline $\begin{array}{l}\text { GREEF e FREITAS } \\
(2012)\end{array}$ & $\begin{array}{l}\text { Dimensões e atributos de qualidade da informação propostos por Silva (2003) e De } \\
\text { Sordi (2008) com base em Huang, Lee e Wang (1999) }\end{array}$ \\
\hline ASSIS e MOURA (2012) & $\begin{array}{l}\text { Dimensões e atributos de qualidade da informação propostos por Eppler e Wittig } \\
\text { (2000) e critérios de avaliação de qualidade da informação para Web propostos } \\
\text { por Parker et al. (2006) }\end{array}$ \\
\hline $\begin{array}{l}\text { DE SORDI e MEIRELES } \\
\qquad(2011)\end{array}$ & $\begin{array}{l}\text { Dimensões e atributos de qualidade da informação propostos por De Sordi (2008) } \\
\text { com base em Huang, Lee e Wang (1999) }\end{array}$ \\
\hline $\begin{array}{l}\text { AMARAL e SOUSA } \\
(2011)\end{array}$ & $\begin{array}{l}\text { Dimensões e atributos de qualidade da informação propostos por De Sordi (2008) } \\
\text { com base em Huang, Lee e Wang (1999) }\end{array}$ \\
\hline ABIB (2010) & $\begin{array}{l}\text { Dimensões e atributos de qualidade da informação propostos por Pipino, Lee e } \\
\text { Wang (2002) }\end{array}$ \\
\hline $\begin{array}{l}\text { CALAZANS e COSTA } \\
(2009)\end{array}$ & Dimensões e atributos de qualidade da informação propostos Lee et al. (2002) \\
\hline $\begin{array}{l}\text { DE SORDI e MEIRELES } \\
(2009)\end{array}$ & $\begin{array}{l}\text { Dimensões e atributos de qualidade da informação propostos por De Sordi (2008) } \\
\text { com base em Huang, Lee e Wang (1999) }\end{array}$ \\
\hline DE SORDI (2009) & Dimensões e atributos de qualidade da informação propostos por Eppler (2006) \\
\hline $\begin{array}{l}\text { ALBUQUERQUE, } \\
\text { BASTOS e LINO (2009) }\end{array}$ & $\begin{array}{l}\text { Dimensões e atributos de qualidade da informação propostos por Knight e Burn } \\
\text { (2005) com base em Marchand (1990), Wang e Strong (1996), Alexander e Tate } \\
\text { (1999) e outros. }\end{array}$ \\
\hline $\begin{array}{l}\text { DE SORDI, MEIRELES } \\
\text { e GRIJO (2008) }\end{array}$ & Análise somente da dimensão confiabilidade a partir Huang, Lee e Wang (1999) \\
\hline CALAZANS (2008) & $\begin{array}{l}\text { Revisão de literatura: conceitos e aplicações de qualidade da informação: } \\
\text { Marchand (1989), Ginman (1989), Olaisen (1989), Wang e Strong (1996), Huang, } \\
\text { Lee e Wang (1999), Wand e Wang (1996), Lee, Strong e Kalin (2002), Liu e Chi } \\
\text { (2002), Gackowski (2004; 2005), Nehmy (1996), I. L. Lopes (2004), Oleto (2006) e } \\
\text { outros }\end{array}$ \\
\hline OLETO (2006) & $\begin{array}{l}\text { Dimensões e atributos de qualidade da informação propostos por Paim, Nehmy e } \\
\text { Guimarães (1996) com base em Casanova (1990) }\end{array}$ \\
\hline LOPES (2004) & $\begin{array}{l}\text { Critérios indicadores da qualidade da informação em saúde na Web propostos pela } \\
\text { AHCPR-HSWG (Hiti) e atributos e dimensões de qualidade da informação } \\
\text { propostos por Olaisen (1990), Marchand (1990) e Kahn, Strong e Wang (1997) }\end{array}$ \\
\hline AROUCK (2001) & $\begin{array}{l}\text { Dimensões e atributos de qualidade da informação com base em metodologia de } \\
\text { avaliação de qualidade de serviço proposta por DeLone e McLean (1992) e outros }\end{array}$ \\
\hline NEHMY, PAIM (1998) & $\begin{array}{l}\text { Dimensões e atributos de qualidade da informação propostos por Marchand (1990) } \\
\text { e classificações de Repo (1989) e Olaisen (1990) }\end{array}$ \\
\hline $\begin{array}{l}\text { PAIM, NEHMY e } \\
\text { GUIMARÃES (1996) }\end{array}$ & $\begin{array}{l}\text { Dimensões e atributos de qualidade da informação baseados na proposta de } \\
\text { Marchand (1990) e classificações de Repo (1989), Olaisen (1990) }\end{array}$ \\
\hline
\end{tabular}

Fonte: Elaborado pelas autoras. 
Foram considerados os estudos que focassem especificamente 0 tema qualidade de informação mencionando atributos, dimensões ou categorias de qualidade utilizadas para qualificar a informação, ainda que em contextos diferentes. A partir do estudo e análise detalhada de cada um desses trabalhos, foram identificados e relacionados todos os atributos, categorias e dimensões de qualidade mencionados pelos autores nacionais em seus estudos, bem como os autores internacionais. Os atributos, dimensões e categorias de qualidade da informação levantados foram transcritos em planilhas do aplicativo Excel para serem mais bem organizados e sintetizados. Após o levantamento geral, realizou-se uma classificação por ordem alfabética e, posteriormente, os termos sinônimos e/ou semelhantes, com significados similares foram sendo agrupados em uma mesma categoria com base na literatura pesquisada. Depois de classificados e organizados, os dados foram sintetizados primeiramente em um quadro geral com todos os atributos e dimensões de qualidade mencionados nos estudos nacionais da CI que serviram de base a esta pesquisa. Nesse quadro geral, optou-se por manter todos os termos e nomenclaturas encontrados nos artigos analisados para qualificar a informação, ainda que se tenha feito o agrupamento dando destaque ao termo mais recorrente. Tal escolha foi intencional visando contribuir para que estudos posteriores possam se orientar para possíveis classificações e agrupamentos de termos similares ou com significados semelhantes, uma vez que recorrentemente aparecem com nomenclaturas diferentes ou, em outras situações, são agrupados de forma diversa nos estudos realizados. Assim, ao se optar por esta forma de classificação e organização espera-se contribuir com estudos posteriores sobre o tema de modo a facilitar a análise dos atributos de qualidade da informação utilizados nos estudos da CI. Posteriormente, foram elaborados quadros e gráficos com a síntese dos agrupamentos de atributos de qualidade mais citados nos estudos nacionais sobre qualidade de informação no campo da CI. Por fim, foi elaborado um quadro comparativo com os atributos de qualidade da informação mais citados nos estudos da CI e os atributos das Características Qualitativas da Informação Contábil-Financeira Útil pertencentes à Estrutura Conceitual da Contabilidade, a partir do qual se analisam as similaridades e diferenças entre os atributos e dimensões qualificadoras da informação nos dois campos do conhecimento: CC e CI. São esses que embasam os resultados e análises apresentadas no item 4. Resultados deste estudo.

\section{Referencial teórico}

\subsection{Informação}

Considerando que a concepção de informação nas duas áreas do conhecimento abrangidas por este estudo são diferentes, faz-se necessário contextualizar o conceito em cada uma das áreas. Na Ciência 
da Informação, o conceito de informação envolve diferentes concepções, mais ou menos abrangentes. Para Buckland (1991) o significado do termo "informação" está relacionado ao seu uso, podendo ser concebida sob três aspectos: i) informação como processo; ii) informação como conhecimento e iii) informação como coisa. Concebida como processo, a informação é o ato de informar um dado, fato, evento, documento ou objeto cuja relevância depende do nível de conhecimento do receptor, sendo, portanto, situacional. Como conhecimento, tem como uma de suas formas, a sua capacidade para a redução de incertezas. Entendida como coisa, a informação está relacionada "[...] aos objetos que são considerados como sendo informativos em suas características físicas, tais como o dado e os documentos expressos, descritos ou representados por alguma forma física como o sinal, o texto ou a comunicação desses" (BUCKLAND, 1991, p. 351-360). Entretanto, Le Coadic (1996) delimita o conceito de informação ao conhecimento inscrito (sob a forma escrita, oral ou audiovisual), que comporta elemento de sentido e é transmitida a seres conscientes por meio de mensagens inscritas. Assim, neste estudo, optou-se por adotar o conceito de informação de Smit e Barreto (2002) que entendem informação como:

estruturas simbolicamente significantes, codificadas de forma socialmente decodificável e registradas (para garantir permanência no tempo e no espaço) e que apresentam a competência de gerar conhecimento para o indivíduo e para o seu meio (SAMIR; BARRETO, 2002, p. 21).

A escolha desta concepção se respalda em Fujino e Jacomini (2007, p. 74) para quem essa definição de informação "[...] traz implícita a competência para gerar conhecimento no potencial usuário, em contextos específicos que definem sua necessidade e uso." e, em Barreto (1999), que assinala que o ato não é unidirecional, mas depende da competência dos receptores para a apropriação da informação e das formas de distribuição ou transferência da informação.

No campo das Ciências Contábeis, especialmente no que se refere à informação contábil, a literatura é pródiga em tratar da sua importância, relevância e da sua relação e impacto com os usuários e com o mercado, porém bastante escassa quanto à sua conceituação. Assim, para Amorim (2007, p. 32), "[...] a informação contábil pode ser considerada como aquela que altera o estado da arte do conhecimento de seu usuário em relação à empresa e, a partir de interpretações, utiliza-a na solução de problemas [...]". De natureza econômico-financeira, física e de produtividade, "[...] a informação contábil tem como consequência a ratificação ou alteração da opinião de seus usuários a respeito das atividades da empresa." (AMORIM, 2007, p. 32). 


\subsection{Qualidade da informação}

Embora não haja consenso sobre o conceito de qualidade da informação, observa-se no campo da CI diversas proposições de dimensões, categorias, classes e atributos para qualificar a informação em diferentes aspectos e contextos. Tais propostas fundamentam-se, em sua maioria, em estudos internacionais, norteadas, sobretudo, em Huang, Lee e Wang (1999). Tais atributos, geralmente denominados como dimensões da qualidade, são usados para definir, medir e gerenciar a qualidade dos dados e informações e variam de acordo com as abordagens e vertentes sob as quais os estudos são realizados e de acordo com o contexto onde o conceito de qualidade é aplicado e avaliado. Em alguns desses estudos os termos "dado" e "informação" são tratados como sinônimos não existindo a distinção observada com mais destaque em algumas áreas do conhecimento. É o que observam Knight e Burn (2005) ao afirmarem que tal como acontece com grande parte da pesquisa em Qualidade da Informação (QI) em Sistemas de Informação o termo informação é geralmente intercambiável com dados. Nesse sentido, é importante destacar o argumento de Spender (2001, p. 31):

$\mathrm{Na}$ Ciência da Informação há duas linhas bem definidas e distintas de entendimento sobre a qualidade da informação. A primeira compreende a informação ou conhecimento como objeto ou conteúdo a ser desenvolvido, comprado, possuído ou vendido; sua natureza é explícita e direcionada aos aspectos objetivos da informação. A segunda estabelece um forte vínculo da informação ou conhecimento com as pessoas que o detêm, procuram, utilizam, desenvolvem ou compartilham; apresenta natureza tácita e direcionada aos aspectos subjetivos da informação.

Oleto (2006) complementa e destaca duas abordagens: baseada no produto e com base no usuário. Para o autor, a abordagem baseada no produto tende a avaliar os sistemas de informação a partir do próprio sistema, avaliando itens como projeto, conteúdo, atendimento ao usuário, sendo esta "[...] mais propícia à operacionalização dos conceitos e mais voltada para aspectos objetivos." Já a abordagem baseada no usuário tende "[...] a avaliar os sistemas de informação a partir de considerações centradas na pessoa e enfocando aspectos mais subjetivos [...]" (OLETO, 2006, p. 3). Respaldando-se nos estudos de Casanova (1990), Nehmy (1996) e Paim, Nehmy e Guimarães (1996), Oleto (2006) destaca que a abordagem de análise da qualidade da informação baseada no produto enfatiza a informação como coisa, atribuindo-se à qualidade da informação os seguintes atributos ou dimensões, apresentados em destaque (grifo nosso) a seguir: Abrangência, relacionada ao valor intrínseco da informação; Acessibilidade, importância em termos de redução do tempo necessário ao acesso à informação; Atualidade, 
referindo-se à consonância com o ritmo de produção da informação, opondo-se à obsolescência; Confiabilidade, em termos da credibilidade no conteúdo e na fonte da informação; relacionada à idéia de autoridade cognitiva: prestígio, respeito, reputação da fonte, autor ou instituição; semelhante a uma espécie de fé; Objetividade, ligada ao valor intrínseco da informação; Precisão, sentido aproximado de exatidão, correção, remetendo à forma de registro fiel ao fato que representa e Validade, pressupondo integridade da fonte de informação e forma de registro fiel ao fato que representa. Segundo o autor, a abordagem da qualidade da informação baseada no usuário tem a sua origem nos anos 70 como resposta às limitações da abordagem objetivista que considerava os sistemas de informação prioritariamente por seu lado técnico e pela eficácia da recuperação da informação. Assim, de acordo com Saracevic (1996) citado por Oleto (2006, p. 4) "[...] o paradigma da recuperação da informação deslocou-se em direção à contextualização mais ampla, voltando-se para os usuários e suas interações [...]". Com base em Saracevic (1996), Paim, Nehmy e Guimarães (1996) e Nehmy e Paim (1998), Oleto (2006) destaca que, nessa abordagem, os atributos da qualidade da informação que geralmente a literatura associa ao usuário são: Adequação da indexação e classificação, atributo do sistema de informação associado à qualidade da informação em termos de 'relevância objetiva', medida de adequação entre fonte e destinatário da informação; Eficácia; Eficiência da recuperação; Impacto; Relevância; Utilidade equivalente à relevância; refere-se ao valor de uso da informação na perspectiva de quem ou para que será útil; Valor de uso - caráter cognitivo que leva em consideração o usuário, o uso e os efeitos no trato da informação; Valor esperado e Valor Percebido. Elencados e mencionados por diferentes autores, conforme aponta a abrangente revisão da literatura de Casanova (1990), tais atributos também denominados como dimensões ou categorias de qualidade ou valor da informação são discutidos no estudo de Paim, Nehmy e Guimarães (1996, p.115) para evidenciar as três grandes vertentes sob as quais o tema é abordado na literatura:

Valor Transcendente - implica o reconhecimento do valor da informação como absoluto e universalmente aceitável, aproximando-se da idéia de excelência; sendo extratemporal e permanente. Pressupõe a existência de uma essência de qualidade da informação independente do tempo-espaço histórico. "Não pode ser atingido em si, mas é dependente do ponto de vista do usuário."

Valor intrínseco - referem-se aos valores inerentes ao dado, documento ou informação.

Valor contingencial - atributos relacionados ao contexto ou ao usuário da informação.

Para esses autores, os aspectos que incorporam qualidade à informação em cada uma dessas vertentes são: 
Validade - atributo que confere valor real à informação. Pressupõe integridade da fonte de informação e forma de registro fiel ao fato que representa.

- Confiabilidade - atributo que confere valor real à informação. Credibilidade no conteúdo e na fonte da informação. Relacionada à idéia de autoridade cognitiva - prestígio, respeito, reputação da fonte, autor ou instituição. Assemelha-se a uma espécie de fé.

- Precisão - atributo que confere valor real à informação. Sentido aproximado de exatidão, correção; remete à forma de registro fiel ao fato representado.

- Completeza - implica a inclusão de todos os dados necessários relativo a um determinado problema.

- Novidade - representa o novo, o recente.

- Atualidade - implica consonância com o ritmo de produção da informação, opondo-se à obsolescência.

- Valor percebido - refere-se à compreensão do sujeito a respeito do valor da informação. Está ligado ao significado subjetivo atribuído à informação.

- Eficácia - significa o grau de adequação da informação na solução do problema do sujeito-usuário da informação. Decorre do uso da informação. A informação será eficaz se contribuir para algum resultado positivo para o sujeito da ação. (Ex. tomada de decisão adequada).

- Relevância - significa medida do contato eficaz entre uma fonte e um destinatário.

- Abrangência - diz respeito ao volume de dados necessários para que a informação se torne eficaz.

- Redundância - significa o reforço da informação por meio da repetição de dados, tomando-se como parâmetro um determinado usuário. O que pode se apresentar como redundante para um tipo de usuário pode não o ser para outro. Se excessiva tende a diminuir a qualidade da informação. (PAIM; NEHMY; GUIMARÃES, 1996 , p. 115, grifos nossos).

Entretanto, Paim, Nehmy e Guimarães (1996, p. 117) alertam que o "[...] cenário em que se inscreve o conceito de qualidade da informação, marcado pela dicotomia entre atributos intrínsecos e contingenciais, com forte tendência para a hegemonia dos últimos, implica riscos para a leitura e para a provisão da informação." e a inter-relação existente entre os atributos confere multidimensionalidade à qualidade da informação conforme síntese apresentada no Quadro 2. 
Quadro 2 - Modelo multidimensional da qualidade da informação

\begin{tabular}{|c|c|c|c|}
\hline \multicolumn{4}{|c|}{ Dimensões e Atributos } \\
\hline \multirow[b]{2}{*}{ TRANSCENDENTE } & \multirow[b]{2}{*}{ INTRÍNSECA } & \multicolumn{2}{|c|}{ CONTINGENCIAL } \\
\hline & & Usuário & $\begin{array}{l}\text { Formato do } \\
\text { Produto }\end{array}$ \\
\hline $\begin{array}{l}\text { - } \quad \text { Valor filosófico } \\
\text { ou metafísico }\end{array}$ & $\begin{array}{ll}- & \text { Validade } \\
\text { - } & \text { Confiabilidade } \\
\text { - } & \text { Precisão } \\
\text { - } & \text { Completeza } \\
\text { - } & \text { Novidade } \\
\text { - } & \text { Pertinência } \\
\text { - } & \text { Atualidade } \\
\text { - } & \text { Significado } \\
\text { através do tempo } \\
\text { - } & \text { Abrangência }\end{array}$ & $\begin{array}{ll}\text { - } & \text { Valor } \\
\text { percebido } \\
\text { - } & \text { Eficácia } \\
\text { - } & \text { Relevância } \\
\text { - } & \text { Redundância }\end{array}$ & $\begin{array}{ll}- & \text { Eletrônico } \\
\text { - } & \text { Impresso } \\
\text { - } & \text { Oral } \\
\text { - } & \text { Microforma } \\
\text { - } & \text { Integral } \\
\text { - } & \text { Sintético } \\
\text { - } & \text { Formal } \\
\text { - } & \text { Informal }\end{array}$ \\
\hline
\end{tabular}

Fonte: Adaptado de PAIM; NEHMY; GUIMARÃES (1996, p. 115).

Comentando sobre as muitas formas de categorização das dimensões da qualidade da informação esquematizadas por diferentes autores sob vários âmbitos ou aspectos, De Sordi, Meireles e Grijo (2008) citam a lista desenvolvida por Huang, Lee e Wang (1999) composta por quatro categorias e quinze dimensões de análise da informação conforme mostra o Quadro 3, a seguir.

Quadro 3 - Categorias e dimensões de qualidade da informação

\begin{tabular}{|c|c|}
\hline Categorias & Dimensões \\
\hline Intrínseca & $\begin{array}{l}\text { Acurácia, Objetividade, Credibilidade e } \\
\text { Reputacão }\end{array}$ \\
\hline Acessibilidade & Acesso e Segurança \\
\hline Contextual & $\begin{array}{l}\text { Relevância, Valor Agregado, Economia de } \\
\text { Tempo, Completude e Quantidade de } \\
\text { Dados }\end{array}$ \\
\hline Representacional & $\begin{array}{l}\text { Interpretabilidade, Facilidade de Uso, } \\
\text { Representação Concisa e Representação } \\
\text { Consistente }\end{array}$ \\
\hline
\end{tabular}

Fonte: Adaptado de HUANG; LEE; WANG (1999).

Os autores argumentam que tais dimensões não são facilmente identificadas, requerendo análise e consenso entre geradores, leitores e demais interessados. Complementando e avançando em relação às dimensões propostas por Huang, Lee e Wang (1999), De Sordi (2008) listou também diferentes dimensões e atributos para a qualificação das informações conforme evidenciado no Quadro 4, a seguir.

Quadro 4 - Dimensões e atributos de qualidade da informação

\begin{tabular}{l|l}
\hline Dimensões da Informação & Atributos da Informação \\
\hline \hline Acurácia / Veracidade & $\begin{array}{l}\text { Nível de acurácia; e método para determinação do nível de } \\
\text { acurácia }\end{array}$ \\
\hline Atualidade / Temporalidade & $\begin{array}{l}\text { Data da geração da informação; horário de geração da } \\
\text { informação; e intervalo de tempo entre cada nova geração } \\
\text { de informação }\end{array}$ \\
\hline
\end{tabular}




\begin{tabular}{l|l}
\hline Disponibilidade & $\begin{array}{l}\text { Meio de acesso à informação; horário de disponibilização } \\
\text { da informação; e tempo decorrido entre a solicitação e o } \\
\text { acesso à informação }\end{array}$ \\
\hline Confidencialidade / Privacidade & $\begin{array}{l}\text { Público-alvo; e predileções informacionais do público-alvo } \\
\text { Existência }\end{array}$ \\
\hline localização do algoritmo para geração da informação; e \\
lbrangência / Escopo & Vetores da informazcenamento do conteúdo informacional \\
\hline Integridade & Nível de integridade da informação \\
\hline Ineditismo / Raridade & Disponibilidade de informações idênticas ou similares \\
\hline Contextualização & Caracterização da informação \\
\hline Precisão & Nível de precisão da informação \\
\hline Confiabilidade & Credibilidade da fonte; e credibilidade do conteúdo \\
\hline Originalidade & Originalidade da informação \\
\hline Pertinência / Agregação de Valor & $\begin{array}{l}\text { Valor potencial da informação } \\
\text { Valor entregue pela informação }\end{array}$ \\
\hline ldentidade & Nome; sinônimos; e autoria \\
\hline Audiência & Frequência de acesso; e duração de tempo de acesso \\
\hline
\end{tabular}

Fonte: Adaptado de DE SORDI, 2008.

De acordo com a literatura, apesar de não existir uma definição padrão única para qualidade, alguns autores concordam que assim como no gerenciamento de produtos físicos, a qualidade da informação tem múltiplas dimensões. Nesse sentido Arouck (2011) realizou uma pesquisa exploratória com vistas a identificar e analisar os atributos de qualidade da informação presentes nos estudos da Ciência da Informação relacionados à gestão de sistemas e serviços de informação publicados em língua inglesa no período de 1974 a 2009. O autor categorizou os referidos atributos de acordo com os três níveis do problema da comunicação (meio, conteúdo e uso) segundo Shanon e Weaver. A síntese da proposta de categorização/agrupamento dos atributos de qualidade da informação de Arouck (2011) é apresentada no Quadro 5 que se reproduz a seguir:

Quadro 5 - Categorias e atributos de qualidade da informação

Categorias e atributos

\begin{tabular}{l|l|l|l}
\hline Categorias & \multicolumn{1}{|c|}{ Meio } & \multicolumn{1}{c|}{ Conteúdo } & \multicolumn{1}{c}{ Uso } \\
\hline \multirow{2}{*}{ Atributos } & $\begin{array}{l}\text { Acessibilidade, aparência, } \\
\text { clareza, concisão, formato, } \\
\text { legibilidade, localizabilidade, } \\
\text { mensurabilidade, ordem, } \\
\text { quantidade, segurança, } \\
\text { simplicidade, } \\
\text { singularidade,tempestividade, } \\
\text { tempo de resposta, volume. }\end{array}$ & $\begin{array}{l}\text { Abrangência, } \\
\text { atualidade, coerência, } \\
\text { completude, } \\
\text { confiabilidade, } \\
\text { correção, credibilidade, } \\
\text { imparcialidade, } \\
\text { inequivocidade, } \\
\text { logicidade, precisão, } \\
\text { validade, veracidade. }\end{array}$ & $\begin{array}{l}\text { Compatibilidade, } \\
\text { compreensibilidade, } \\
\text { conveniência, importância, } \\
\text { interpretabilidade, } \\
\text { pertinência, relevância, } \\
\text { significância, suficiência, } \\
\text { utilidade, valor informativo. }\end{array}$ \\
\hline
\end{tabular}

Fonte: AROUCK (2011, p. 91). 


\subsection{Qualidade da informação contábil}

De acordo com os autores da literatura contábil (HENDRIKSEN; BREDA, 1999; IUDÍCIBUS, 2006), o desenvolvimento da Contabilidade como ciência social tem como objetivo o atendimento das demandas de informação requeridas pelos diferentes tipos de usuários. Segundo a abordagem da Informação e a Teoria Positiva da Contabilidade, dados financeiros e relatórios contábeis tem a sua importância aumentada no contexto de tomada de decisões à medida que as organizações ficam mais complexas. É por essa razão que, segundo Ijiri (1975), a Contabilidade deve seguir certas regras e adaptar-se às mudanças ambientais, para não correr o risco de ser mal interpretada no seu processo de comunicação e em seu objetivo de serem úteis para orientar decisões. A perspectiva contábil baseada na informação, mais conhecida como information approach (abordagem da informação) é assim denominada porque considera a Contabilidade como um meio de transmissão de informação vinculada à Teoria da Comunicação. Nessa ótica, a Contabilidade preocupa-se com a utilidade da informação contábil para investidores e outros usuários, um pragmatismo direcionado para a Teoria Positiva da Contabilidade (LOPES, 2002). Analisada sob a ótica da Teoria Matemática da Comunicação que envolve os elementos: mensagem, emissor, canal, receptor e destinatário (SHANNON; WEAVER, 1949), a Contabilidade segundo Dias Filho (2000) deve preocupar-se, sobretudo, com a eficácia da sua linguagem em relação à quantidade de informação assimilada e ao volume de alternativas que tais informações possibilitam ao usuário descartar. Segundo o autor a informação contábil possibilita a redução de incertezas. Assim, a validade da informação contábil pode ser determinada pela diferença do nível de incerteza do usuário antes e depois de receber a mensagem. Vem daí a importância de que as informações contábeis sejam revestidas de atributos que permitam conferir-lhe maior grau de qualidade de forma a efetivamente ser útil aos seus usuários.

\subsection{Características qualitativas da informação contábil- financeira útil}

Hendriksen e Breda (1999) definem as características qualitativas como as propriedades da informação que são necessárias para torná-la útil. Segundo os autores, a utilidade da Contabilidade como sistema de informação depende de sua capacidade de informar aos vários grupos de interesse associados à empresa. Para Lopes e Martins (2005, p. 114) as características específicas da informação contábil podem ser relacionadas aos usuários ou às decisões tomadas. Tais características de qualidade fazem parte de um framework denominado Estrutura Conceitual. A Estrutura Conceitual vigente no Brasil foi atualizada e teve sua redação alterada pela Resolução CFC Nr. 1.374, de 2011, do Conselho Federal de Contabilidade (CFC) para ajustar-se ao Pronunciamento Conceitual Básico 
(R1) do Comitê de Pronunciamentos Contábeis (CPC) com base no The Conceptual Framework for Financial Reporting (IASB-BV 2011 Blue Book). A referida Estrutura Conceitual denominada NBC TG ESTRUTURA CONCEITUAL - Estrutura Conceitual para Elaboração e Divulgação de Relatório Contábil-Financeiro estabelece que:

[...] as características qualitativas da informação contábilfinanceira útil [...] identificam os tipos de informação que muito provavelmente são reputadas como as mais úteis para investidores, credores por empréstimos e outros credores, existentes e em potencial, para tomada de decisões acerca da entidade que reporta com base na informação contida nos seus relatórios contábil-financeiros (informação contábilfinanceira) (CFC, 2011, p. 11).

Ainda de acordo com a nova Estrutura Conceitual, as "Características Qualitativas da Informação Contábil-financeira Útil" devem ser aplicadas não somente à informação contábil- financeira fornecida por meio das Demonstrações Contábeis, mas, também à toda informação contábil-financeira fornecida por outros meios. Com as modificações realizadas, na nova versão da Estrutura Conceitual (CFC, 2011) atualmente em vigor no Brasil, as "Características Qualitativas da Informação Contábil-financeira Útil" foram divididas em dois grupos, detalhados no Quadro 6 apresentado a seguir.

Quadro 6 - Características qualitativas da informação contábil-financeira útil

\begin{tabular}{|c|c|c|c|}
\hline \multicolumn{4}{|c|}{$\begin{array}{l}\text { Características Qualitativas da Informação Contábil-Financeira Útil (IASB - } \\
\text { CPC/CFC) }\end{array}$} \\
\hline \multicolumn{4}{|c|}{$\begin{array}{l}\text { Características Qualitativas Fundamentais } \\
\text { (fundamental qualitative characteristics) } \\
\text { Características mais críticas }\end{array}$} \\
\hline \multicolumn{2}{|c|}{ Relevância } & \multicolumn{2}{|c|}{ Representação Fidedigna } \\
\hline \multicolumn{2}{|l|}{$\begin{array}{l}\text { Valor preditivo } \\
\text { Valor confirmatório }\end{array}$} & \multicolumn{2}{|c|}{$\begin{array}{l}\text { Completa } \\
\text { Neutra } \\
\text { Livre de erro }\end{array}$} \\
\hline \multicolumn{4}{|c|}{$\begin{array}{l}\text { Características Qualitativas de Melhoria } \\
\text { (enhancing qualitative characteristics) } \\
\text { Características altamente desejáveis }\end{array}$} \\
\hline Comparabilidade & Verificabilidade & Tempestividade & Compreensibilidade \\
\hline $\begin{array}{ll}- & \text { Consistência } \\
- & \text { Uniformidade }\end{array}$ & & & $\begin{array}{ll}- & \text { Clareza } \\
- & \text { Concisão }\end{array}$ \\
\hline
\end{tabular}

Fonte: Elaborado pelas autoras.

Apresentam-se, a seguir, as definições dadas a cada uma das características qualitativas e correspondentes atributos de qualidade da informação componentes das "Características Qualitativas da Informação Contábil-Financeira Útil" pertencentes à atual Estrutura Conceitual da contabilidade segundo o CPC (2011) e CFC (2011, p. 12-17). 
Relevância é definida na atual Estrutura Conceitual como a característica qualitativa fundamental da informação contábil-financeira que a torna capaz de fazer diferença nas decisões a serem tomadas pelos usuários. Inclui dois atributos de qualidade:

- Valor preditivo - a informação contábil-financeira tem valor preditivo se puder ser utilizada como dado de entrada em processos empregados pelos usuários para predizer futuros resultados

- Valor confirmatório - a informação contábil-financeira tem valor confirmatório se retro-alimentar - servir de feedback - avaliações prévias (confirmá-las ou alterálas).

Representação fidedigna é característica que permite que a informação seja útil tanto em sua capacidade de representar um fenômeno relevante como também de representar com fidedignidade a realidade que se propõe representar. Incluis os atributos:

- Completa - o retrato da realidade econômica completo deve incluir toda a informação necessária para que o usuário compreenda o fenômeno sendo retratado, incluindo todas as descrições e explicações necessárias.

- Neutra - um retrato neutro da realidade econômica é desprovido de viés na seleção ou na apresentação da informação contábil-financeira..

- Livre de erro - significa que o retrato da realidade econômica está livre de erros, não havendo erros ou omissões no fenômeno retratado e que o processo utilizado, para produzir a informação reportada, foi selecionado e foi aplicado livre de erros.

Comparabilidade - característica que melhora a utilidade da informação por permitir que os usuários identifiquem e compreendam similaridades e diferenças entre itens contidos nas informações reportadas pela entidade comparando-os com informações similares sobre outras entidades ou sobre a própria entidade em períodos diferentes, pressupondo a existência dos seguintes atributos:

- Consistência - atributo de qualidade da informação que auxilia no alcance do objetivo da comparabilidade uma vez que se refere ao uso dos mesmos métodos para os mesmos itens, tanto de um período para outro considerando a mesma entidade que reporta a informação, quanto para um único período entre entidades. 
- Uniformidade - atributo de qualidade da informação que auxilia no alcance do objetivo da comparabilidade uma vez que permite que coisas iguais pareçam iguais $e$ coisas diferentes pareçam diferentes.

Verificabilidade - característica qualitativa que melhora a utilidade da informação contábil porque ajuda a assegurar aos usuários que a informação representa fidedignamente o fenômeno econômico que se propõe a representar. Significa que diferentes observadores, cônscios e independentes, podem chegar a um consenso quanto à representação fidedigna do retrato de uma realidade econômica em particular ainda que não cheguem necessariamente a um completo acordo. Pode ser direta ou indireta.

Tempestividade - característica que melhora a utilidade da informação contábil por possibilitar que a informação esteja disponível para tomadores de decisão a tempo de poder influenciá-los em suas decisões.

Compreensibilidade - característica qualitativa que melhora a utilidade da informação contábil por possibilitar que a informação seja classificada, caracterizada e apresentada de forma a se tornar compreensível. A característica qualitativa compreensibilidade pressupõe que a informação contábil-financeira possua os seguintes atributos de qualidade:

- Clareza - atributo de qualidade imprescindível para que a característica qualitativa de melhoria da informação contábil-financeira "compreensibilidade" seja atingida.

- Concisão - atributo de qualidade imprescindível para que a característica qualitativa de melhoria da informação contábil-financeira "compreensibilidade" seja atingida.

\section{Resultados}

\subsection{Atributos e dimensões de qualidade da informação na Ciência da Informação}

Apresenta-se no Gráfico 1, a seguir, uma síntese dos atributos mais citados nos estudos nacionais da CI, que fundamentaram o presente estudo, conforme descritos no item 2. Método da Pesquisa, destacando-se aqueles que foram mencionados por mais de três vezes nos trabalhos analisados. 
Gráfico 1 - Atributos de qualidade da informação mais citados na literatura nacional da Ciência da Informação

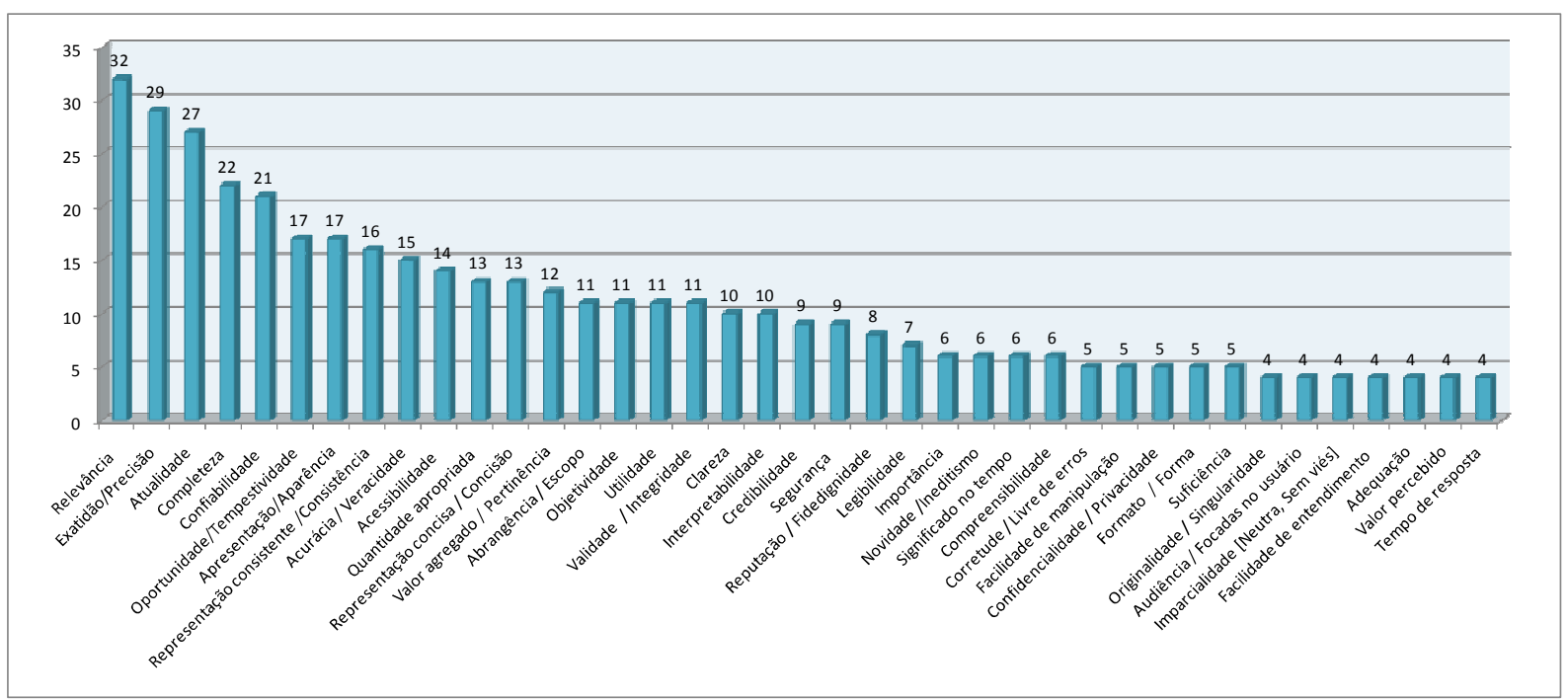

Fonte: Elaborado pelas autoras.

Os resultados diferem dos achados de Arouck (2011) que teve por base a literatura em língua inglesa, especialmente no que se refere ao atributo "Relevância" que no referido estudo aparece com apenas 2 (duas) ocorrências e nesta pesquisa aparece como o atributo de qualidade mais citado.

\subsection{Análise comparativa entre os atributos e dimensões de qualidade da informação nas Ciências Contábeis e na Ciência da Informação}

Apresenta-se neste tópico uma análise comparativa entre os atributos de qualidade mais citados nos estudos nacionais da CI e os atributos pertencentes às "Características Qualitativas da Informação Contábil-Financeira Útil" da Estrutura Conceitual da Contabilidade.

Quadro 7 - Análise comparativa entre os atributos de qualidade da informação da CI e seus equivalentes na Estrutura Conceitual da contabilidade

\begin{tabular}{|c|c|c|}
\hline $\begin{array}{l}\text { No de } \\
\text { vezes } \\
\text { em } \\
\text { que é } \\
\text { citado } \\
\text { na Cl }\end{array}$ & \begin{tabular}{|lr} 
Atributos & de \\
qualidade & da \\
informação & que \\
embasam & os \\
estudos nacionais \\
da Ciência da \\
Informação
\end{tabular} & $\begin{array}{l}\text { Equivalência com os atributos de qualidade pertencentes às } \\
\text { Características Qualitativas da Informação Contábil-financeira } \\
\text { Útil } \\
\text { - Estrutura Conceitual da contabilidade - }\end{array}$ \\
\hline 32 & Relevância & $\begin{array}{l}\text { Relevância - característica qualitativa fundamental da informação contábil, considerada } \\
\text { como uma das mais críticas. }\end{array}$ \\
\hline 29 & Exatidão/Precisão & $\begin{array}{l}\text { Inexistente e não aplicável no campo da Contabilidade em virtude de os relatórios } \\
\text { contábil-financeiros serem baseados em estimativas, julgamentos e modelos e não em } \\
\text { descrições ou retratos exatos. }\end{array}$ \\
\hline
\end{tabular}




\begin{tabular}{|c|c|c|}
\hline 27 & Atualidade & $\begin{array}{l}\text { Atributo de qualidade inexistente na Estrutura Conceitual. Segundo alguns autores da } \\
\mathrm{Cl} \text { pode ser equivalente ao atributo Tempestividade - característica qualitativa de } \\
\text { melhoria da informação contábil-financeira, considerada menos crítica, mas, altamente } \\
\text { desejável. }\end{array}$ \\
\hline 22 & Completeza & $\begin{array}{l}\text { Equivalente ao atributo de qualidade "Completa" da característica qualitativa } \\
\text { fundamental "Representação fidedigna", considerado essencial para que a } \\
\text { informação contábil-financeira represente com fidedignidade a realidade retratada, o } \\
\text { fenômeno que se propõe a retratar. }\end{array}$ \\
\hline 21 & Confiabilidade & $\begin{array}{l}\text { Atributo de qualidade inexistente na Estrutura Conceitual vigente. Na antiga Estrutura } \\
\text { Conceitual era considerada uma das principais características de qualidade da } \\
\text { informação. Na nova Estrutura Conceitual foi redenominada de "representação } \\
\text { fidedigna". }\end{array}$ \\
\hline 17 & $\begin{array}{l}\text { Oportunidade/ } \\
\text { Tempestividade }\end{array}$ & $\begin{array}{l}\text { Tempestividade - característica qualitativa de melhoria da informação contábil- } \\
\text { financeira, considerada menos crítica, mas, altamente desejável. }\end{array}$ \\
\hline 17 & $\begin{array}{l}\text { Apresentação/ } \\
\text { Aparência }\end{array}$ & $\begin{array}{l}\text { Atributos de qualidade da informação não considerados na Estrutura Conceitual da } \\
\text { contabilidade. Não existe na Estrutura Conceitual nenhum atributo de qualidade que se } \\
\text { refira especificamente à forma e apresentação da informação. }\end{array}$ \\
\hline 16 & $\begin{array}{l}\text { Representação } \\
\text { consistente/ } \\
\text { Consistência }\end{array}$ & $\begin{array}{l}\text { "Consistência" - atributo de qualidade da informação pertencente à característica } \\
\text { qualitativa de melhoria "Comparabilidade" considerado auxiliar para o alcance do } \\
\text { objetivo da "Comparabilidade" das informações contábil-financeiras. }\end{array}$ \\
\hline 15 & $\begin{array}{l}\text { Acurácia } \\
\text { Veracidade }\end{array}$ & $\begin{array}{l}\text { Atributos de qualidade da informação inexistente na Estrutura Conceitual da } \\
\text { contabilidade. Porém pode ser considerado como pertencente à característica } \\
\text { qualitativa fundamental "Representação fidedigna". }\end{array}$ \\
\hline 14 & Acessibilidade & $\begin{array}{l}\text { Atributo de qualidade da informação inexistente na Estrutura Conceitual da } \\
\text { contabilidade. Não há na Estrutura Conceitual qualquer menção ao aspecto da } \\
\text { acessibilidade da informação contábil-financeira. }\end{array}$ \\
\hline 13 & $\begin{array}{l}\text { Quantidade } \\
\text { apropriada }\end{array}$ & $\begin{array}{l}\text { Atributo de qualidade da informação inexistente na Estrutura Conceitual da } \\
\text { contabilidade. Porém pode ser considerado como pertencente ao atributo de qualidade } \\
\text { "Completa" da característica qualitativa fundamental "Representação fidedigna". }\end{array}$ \\
\hline 13 & $\begin{array}{l}\text { Concisão } \\
\text { Representação } \\
\text { concisa }\end{array}$ & $\begin{array}{l}\text { "Concisão" - atributo de qualidade da característica qualitativa de melhoria } \\
\text { "Compreensibilidade". Juntamente com o atributo de qualidade "Clareza" são } \\
\text { considerados na Estrutura Conceitual da contabilidade como importantes para tornar a } \\
\text { informação compreensível. }\end{array}$ \\
\hline 12 & $\begin{array}{l}\text { Valor agregado / } \\
\text { Pertinência }\end{array}$ & $\begin{array}{l}\text { Equivalente aos atributos de qualidade "Valor preditivo" e "Valor confirmatório" } \\
\text { pertencentes à característica qualitativa fundamental "Relevância", importantes para } \\
\text { que a informação contábil-financeira seja capaz de fazer diferença nas decisões. }\end{array}$ \\
\hline 11 & $\begin{array}{l}\text { Abrangência } \\
\text { Escopo }\end{array}$ & $\begin{array}{l}\text { Atributo de qualidade da informação inexistente na Estrutura Conceitual da } \\
\text { contabilidade. } \\
\text { Porém pode ser entendido como parte integrante do atributo de qualidade "Completa" } \\
\text { pertencente à característica qualitativa fundamental "Representação fidedigna" uma } \\
\text { vez que o contexto onde as informações contábeis foram geradas e divulgadas devem } \\
\text { ser reportados nos relatórios contábil-financeiros. }\end{array}$ \\
\hline 11 & Objetividade & $\begin{array}{l}\text { Inexistente e não aplicável no campo da Contabilidade pelo fato de os relatórios } \\
\text { contábil-financeiros serem baseados em estimativas, julgamentos e modelos e não em } \\
\text { descrições ou retratos exatos. } \\
\text { Porém, em se tratando da objetividade na forma da comunicação das informações } \\
\text { contábil-financeiras seria um atributo altamente desejável. }\end{array}$ \\
\hline 11 & Utilidade & $\begin{array}{l}\text { Não é considerado um atributo de qualidade e nem uma característica qualitativa da } \\
\text { informação na Estrutura Conceitual da contabilidade, mas, a finalidade, o objetivo da } \\
\text { elaboração e divulgação de relatório contábil-financeiro de propósito geral, ou seja, das } \\
\text { informações contábil-financeiras. Tais objetivos são considerados como o pilar da } \\
\text { Estrutura Conceitual. }\end{array}$ \\
\hline 11 & $\begin{array}{l}\text { Validade/ } \\
\text { Integridade }\end{array}$ & $\begin{array}{l}\text { Atributo de qualidade da informação inexistente na Estrutura Conceitual da } \\
\text { contabilidade. }\end{array}$ \\
\hline 10 & Clareza & $\begin{array}{l}\text { "Clareza" - atributo de qualidade da característica qualitativa de melhoria } \\
\text { "Compreensibilidade". Juntamente com o atributo de qualidade "Concisão" são } \\
\text { considerados na Estrutura Conceitual da contabilidade como importantes para tornar a } \\
\text { informação compreensível. }\end{array}$ \\
\hline 10 & Interpretabilidade & $\begin{array}{l}\text { Atributo de qualidade da informação inexistente na Estrutura Conceitual da } \\
\text { contabilidade. }\end{array}$ \\
\hline 9 & Credibilidade & $\begin{array}{l}\text { Atributo de qualidade da informação inexistente na Estrutura Conceitual da } \\
\text { contabilidade. }\end{array}$ \\
\hline 9 & Segurança & $\begin{array}{l}\text { Atributo de qualidade da informação inexistente na Estrutura Conceitual da } \\
\text { contabilidade. }\end{array}$ \\
\hline
\end{tabular}




\begin{tabular}{|c|c|c|}
\hline 8 & $\begin{array}{l}\text { Reputação/ } \\
\text { Fidedignidade }\end{array}$ & $\begin{array}{l}\text { "Representação fidedigna" - característica qualitativa fundamental para que a } \\
\text { informação contábil-financeira seja útil. }\end{array}$ \\
\hline 7 & Legibilidade & $\begin{array}{l}\text { Atributo de qualidade da informação inexistente na Estrutura Conceitual da } \\
\text { contabilidade. }\end{array}$ \\
\hline 6 & Importância & $\begin{array}{l}\text { Atributo de qualidade da informação inexistente na Estrutura Conceitual da } \\
\text { contabilidade. }\end{array}$ \\
\hline 6 & $\begin{array}{l}\text { Novidade/ } \\
\text { Ineditismo }\end{array}$ & $\begin{array}{l}\text { Atributo de qualidade da informação inexistente na Estrutura Conceitual da } \\
\text { contabilidade. Ressalte-se que em muitos casos os relatórios contábil-financeiros } \\
\text { possuem maior valor confirmatório considerando a defasagem de tempo entre a } \\
\text { ocorrência de um determinado fato ou evento econômico e o reconhecimento e } \\
\text { divulgação do mesmo à sociedade. }\end{array}$ \\
\hline 6 & $\begin{array}{l}\text { Significado } \\
\text { tempo }\end{array}$ & $\begin{array}{l}\text { Atributo de qualidade da informação inexistente na Estrutura Conceitual da } \\
\text { contabilidade. }\end{array}$ \\
\hline 6 & Compreensibilidade & $\begin{array}{l}\text { "Compreensibilidade" - característica qualitativa de melhoria da utilidade da } \\
\text { informação contábil-financeira. Porém os itens QC31 e QC32 que tratam } \\
\text { especificamente dessa característica qualitativa da informação na Estrutura Conceitual } \\
\text { reconhecem que certos fenômenos por serem inerentemente complexos não são } \\
\text { facilmente compreendidos. Ressaltam, entretanto, que embora a exclusão de tais } \\
\text { fenômenos dos relatórios pudessem tornar as informações mais compreensíveis, a sua } \\
\text { inclusão na totalidade é preferível para não comprometer a completude das } \\
\text { informações evitando assim sua potencial distorção. Evidencia-se ainda que os } \\
\text { relatórios contábil-financeiros são destinados a usuários com conhecimento razoável } \\
\text { de negócios e atividades econômicas e que mesmo esses poderão ter necessidade de } \\
\text { buscar a ajuda de especialistas para a compreensão da informação sobre algum } \\
\text { fenômeno econômico complexo. } \\
\text { De modo que ainda que o atributo "compreensibilidade" tenha sido incluído na } \\
\text { Estrutura Conceitual, ao que parece, tal atributo é preterido em relação às demais } \\
\text { características qualitativas da informação. }\end{array}$ \\
\hline 5 & $\begin{array}{l}\text { Corretude / } \\
\text { Livre de erros }\end{array}$ & $\begin{array}{l}\text { O atributo "Livre de erro" é apresentado na Estrutura Conceitual da contabilidade } \\
\text { como um dos atributos de qualidade da informação pertencentes à característica } \\
\text { qualitativa fundamental "Representação fidedigna". Juntamente com os atributos } \\
\text { "Completa" e "Neutra" é considerado como atributo essencial para que a informação } \\
\text { contábil-financeira represente com fidedignidade a realidade retratada, o fenômeno que } \\
\text { se propõe a retratar. }\end{array}$ \\
\hline 5 & $\begin{array}{l}\text { Facilidade } \\
\text { manipulação }\end{array}$ & $\begin{array}{l}\text { Atributo de qualidade da informação inexistente na Estrutura Conceitual da } \\
\text { contabilidade. }\end{array}$ \\
\hline 5 & $\begin{array}{l}\text { Confidencialidade/ } \\
\text { Privacidade }\end{array}$ & $\begin{array}{l}\text { Atributos de qualidade da informação inexistentes e não aplicáveis no campo da } \\
\text { Contabilidade pelo fato de as informações contábil-financeiras serem destinadas a } \\
\text { usuários externos, devendo, portanto, serem essencialmente públicas. }\end{array}$ \\
\hline 5 & Formato / Forma & $\begin{array}{l}\text { Atributos de qualidade da informação inexistentes na Estrutura Conceitual da } \\
\text { contabilidade. Não existe na Estrutura Conceitual nenhum atributo de qualidade que se } \\
\text { refira especificamente à forma ou formato da informação. }\end{array}$ \\
\hline 5 & Suficiência & $\begin{array}{l}\text { Atributo de qualidade da informação inexistente na Estrutura Conceitual da } \\
\text { contabilidade. Porém pode ser considerado equivalente ao atributo de qualidade } \\
\text { "Completa" pertencente à característica qualitativa fundamental "Representação } \\
\text { fidedigna". }\end{array}$ \\
\hline 4 & $\begin{array}{l}\text { Originalidade/ } \\
\text { Singularidade }\end{array}$ & $\begin{array}{l}\text { Atributo de qualidade da informação inexistente na Estrutura Conceitual da } \\
\text { contabilidade. }\end{array}$ \\
\hline 4 & $\begin{array}{l}\text { Audiência/ } \\
\text { Focadas no usuário }\end{array}$ & $\begin{array}{l}\text { Atributo de qualidade da informação inexistente na Estrutura Conceitual da } \\
\text { contabilidade. }\end{array}$ \\
\hline 3 & $\begin{array}{l}\text { Facilidade } \\
\text { de entendimento }\end{array}$ & $\begin{array}{l}\text { Equivalente a característica qualitativa de melhoria "Compreensibilidade" da } \\
\text { Estrutura Conceitual da contabilidade. }\end{array}$ \\
\hline 4 & Adequação & $\begin{array}{l}\text { Atributo de qualidade da informação inexistente na Estrutura Conceitual da } \\
\text { contabilidade. }\end{array}$ \\
\hline 4 & Valor percebido & $\begin{array}{l}\text { Atributo de qualidade da informação inexistente na Estrutura Conceitual da } \\
\text { contabilidade. }\end{array}$ \\
\hline 4 & Tempo de resposta & $\begin{array}{l}\text { Atributo de qualidade da informação inexistente na Estrutura Conceitual da } \\
\text { contabilidade. }\end{array}$ \\
\hline 3 & Contextualização & $\begin{array}{l}\text { Atributo de qualidade da informação inexistente na Estrutura Conceitual da } \\
\text { contabilidade. Porém pode ser entendido como parte integrante do atributo de } \\
\text { qualidade "Completa" pertencente à característica qualitativa fundamental } \\
\text { "Representação fidedigna" uma vez que o contexto onde as informações contábeis } \\
\text { foram geradas e divulgadas devem ser reportados nos relatórios contábil-financeiros. }\end{array}$ \\
\hline 3 & Disponibilidade & $\begin{array}{l}\text { Atributo de qualidade da informação inexistente na Estrutura Conceitual da } \\
\text { contabilidade. Porém pode-se considerar que faz parte da característica qualitativa de } \\
\text { melhoria "Tempestividade". }\end{array}$ \\
\hline
\end{tabular}




\begin{tabular}{l|l|l}
\hline 3 & Eficácia & $\begin{array}{l}\text { Atributo de qualidade da informação inexistente na Estrutura Conceitual da } \\
\text { contabilidade. Porém é mencionado no tópico QC18 da referida Estrutura Conceitual } \\
\text { quando se orienta sobre o processo mais eficaz e efetivo para aplicação das } \\
\text { características qualitativas fundamentais de forma que as informações sejam ao } \\
\text { mesmo tempo relevantes e fidedignas. }\end{array}$ \\
\hline $\mathbf{3}$ & Eficiência & $\begin{array}{l}\text { Atributo de qualidade da informação inexistente na Estrutura Conceitual da } \\
\text { contabilidade. Porém é mencionado no tópico QC18 da referida Estrutura Conceitual } \\
\text { quando se orienta sobre o processo mais eficaz e efetivo para aplicação das } \\
\text { características qualitativas fundamentais de forma que as informações sejam ao } \\
\text { mesmo tempo relevantes e fidedignas. }\end{array}$ \\
\hline $\mathbf{3}$ & Valor informativo & $\begin{array}{l}\text { Equivalente aos atributos de qualidade "Valor preditivo" e "Valor confirmatório" } \\
\text { pertencentes à característica qualitativa fundamental "Relevância", importantes para } \\
\text { que a informação contábil-financeira seja capaz de fazer diferença nas decisões. }\end{array}$ \\
\hline $\mathbf{2}$ & Valor instrutivo & $\begin{array}{l}\text { Equivalente aos atributos de qualidade "Valor preditivo" e "Valor confirmatório" } \\
\text { pertencentes à característica qualitativa fundamental "Relevância", importantes para } \\
\text { que a informação contábil-financeira seja capaz de fazer diferença nas decisões. }\end{array}$ \\
\hline $\mathbf{2}$ & Redundância & $\begin{array}{l}\text { Atributo de qualidade da informação inexistente na Estrutura Conceitual da } \\
\text { contabilidade. }\end{array}$ \\
\hline $\mathbf{2}$ & [Simplicidade & $\begin{array}{l}\text { Atributo de qualidade da informação inexistente na Estrutura Conceitual da } \\
\text { contabilidade. Ao tratar da característica qualitativa de melhoria "Compreensibilidade" } \\
\text { os itens QC31 e QC32 da referida Estrutura Conceitual reconhecem que certos } \\
\text { fenômenos por serem inerentemente complexos não são facilmente compreendidos; e } \\
\text { que os relatórios contábil-financeiros são destinados a usuários com conhecimento } \\
\text { razoável de negócios e atividades econômicas e que mesmo esses poderão ter } \\
\text { necessidade de buscar ajuda de especialistas para a compreensão da informação } \\
\text { sobre algum fenômeno econômico complexo. }\end{array}$ \\
\hline Coesão [Coerência] & $\begin{array}{l}\text { Atributo de qualidade da informação inexistente na Estrutura Conceitual da } \\
\text { contabilidade. }\end{array}$ \\
\hline
\end{tabular}

Fonte: Elaborado pelas autoras.

Importante destacar que os atributos de qualidade identificados na literatura pesquisada não foram renomeados ou redefinidos pelas autoras uma vez que o estudo buscou identificar atributos de qualidade da informação como são citados pelos autores da área e o número de ocorrências nos textos que fundamentaram a análise (conforme descrito no Método da Pesquisa). Assim, o objetivo foi o de comparar as características de cada atributo nomeado pelo autor, a partir das descrições dos próprios autores, para verificar possíveis compatibilidades de características entre os atributos da Ciência da Informação e da Ciência Contábil.

A análise comparativa permite observar que, apesar de algumas similaridades, existem diferenças significativas entre os atributos utilizados para qualificar a informação nas duas áreas de conhecimento. Os dados apresentados no Quadro 7 evidenciam que apesar de muitos atributos de qualidade pertencentes às "Características Qualitativas da Informação Contábil-Financeira Útil" aparecerem listados - com a mesma nomenclatura ou com termos equivalentes - entre os atributos de qualidade da informação mais citados nos estudos nacionais da CI, observam-se diferenças significativas no grau de importância dado pelas duas áreas do conhecimento aos referidos atributos e dimensões de qualidade da informação. Constata-se que a característica qualitativa "Relevância" é o único atributo de qualidade que recebe o mesmo grau de importância nas duas áreas do conhecimento. Já a característica qualitativa "Representação fidedigna" considerada de fundamental importância para a utilidade da informação contábil-financeira, aparece na $22^{\circ}$ posição da lista dos atributos mais citados na literatura nacional da 
CI, tendo sido citado apenas oito vezes. Da mesma forma, a característica qualitativa "Compreensibilidade" pertencente ao grupo das características de melhoria da qualidade da informação contábil-financeira, considerada menos crítica, mas altamente desejável para que as informações contábeis sejam efetivamente úteis, aparece em 270 lugar na lista dos atributos de qualidade mais citados nos estudos da CI, tendo sido mencionado apenas seis vezes. Porém, se for acrescentada a esse atributo de qualidade a frequência de menções dada aos atributos de qualidade "Clareza", "Representação Concisa/Concisão" e "Facilidade de Entendimento" chega-se a um total de trinta e três menções, ficando esse possível agrupamento de atributos de qualidade como o mais citado na literatura nacional da CI. Tal resultado condiz com os pressupostos de qualidade da informação na CI uma vez que nesse campo do conhecimento o atributo compreensibilidade equivale a "potencial de vir a ser apropriado pelo usuário" e está na base do conceito de Informação segundo Le Coadic (1996) e Smit e Barreto (2002).

"Comparabilidade" que nas Ciências Contábeis se refere essencialmente ao conteúdo das informações em relação aos critérios pelos quais são elaboradas e divulgadas, na Ciência da Informação é um atributo que se refere prioritariamente ao formato da informação. Convém destacar, entretanto, que na CI não há como separar forma de conteúdo. O que existe é "equivalência entre termos" utilizada na construção de tesauros para facilitar a pesquisa por parte de usuários. Nas Ciências Contábeis a comparabilidade das informações é necessária para fins de análise entre informações de empresas diferentes ou da mesma empresa em períodos diversos. Na CI a comparabilidade está relacionada aos "termos equivalentes" que são pré-definidos, sendo, portanto, um atributo importante para aumentar o potencial de busca/recuperação e essencial na "construção de vocabulários controlados". É possível observar que muitos atributos, apesar de essenciais para a CI, não são explicitados e mencionados nos estudos sobre qualidade da informação na referida área do conhecimento. É o caso dos atributos: Verificabilidade e Materialidade. Levando em conta que tais atributos estão na base do conceito de Informação para a CI, entende-se como redundante a sua inclusão como atributos de qualidade da informação, justificando-se, portanto, a inexistência de menção a esses atributos nos estudos da Ciência da Informação. Outros atributos, no entanto, pertencentes a essa mesma categoria, apesar de aparecerem com terminologias diferentes nos estudos da Ciência da Informação, podem ser considerados similares aos pertencentes às características qualitativas principais da informação contábil. É o caso dos atributos: "Valor preditivo", "Valor confirmatório" conforme mostrado no Quadro 7.

Por outro lado, verifica-se que atributos importantes para qualificar a informação nos estudos da Ciência da Informação não são considerados para a determinação da qualidade da informação nas Ciências Contábeis. Com exceção dos atributos que efetivamente não se aplicam para a determinação da qualidade das informações contábeis, evidenciados e 
comentados no Quadro 7, observa-se que na composição das "Características Qualitativas da Informação Contábil-Financeira Útil" também não estão contemplados os atributos: "Confiabilidade", "Acessibilidade", "Validade/Integridade", "Interpretabilidade", "Credibilidade", "Legibilidade" e, sobretudo "Redundância" e seus correlatos relacionados à apresentação, aparência e formato das informações. A despeito do entendimento de alguns autores levar a concluir que os aspectos relacionados aos atributos "Confiabilidade", "Validade/Integridade" e "Credibilidade" poderiam ser incorporados à característica qualitativa fundamental "Representação Fidedigna" e que "Interpretabilidade" e "Legibilidade" poderiam se equivaler à característica qualitativa "Compreensibilidade", observam-se, no entanto, diferenças entre as terminologias adotadas para designar os referidos atributos, bem como modificações sutis na descrição dos aspectos avaliados em cada um desses atributos de qualidade. Como exemplo pode-se mencionar os atributos "Confiabilidade" e "Credibilidade" que nos estudos da CI aparecem elencados separadamente apesar das semelhanças inerentes. Somados, ocupariam a $2^{a}$ posição entre os atributos de qualidade da informação mais citados nos estudos da CI. Destaque-se ainda o fato de que "Confiabilidade" considerada como uma das principais características qualitativas da antiga Estrutura Conceitual vigente até 2010 foi suprimida na nova Estrutura Conceitual (CFC, 2011) por entender-se que tal aspecto é inerente à característica qualitativa fundamental "Representação Fidedigna". Os fundamentos e implicações dessa mudança merecem estudos mais aprofundados considerando-se a importância desse atributo para a qualidade da informação.

Entretanto, os atributos de qualidade relacionados à aparência e formato das informações, bem como o atributo denominado "Redundância", mencionado nos estudos da Ciência da Informação, não tem similar nas "Características Qualitativas da Informação ContábilFinanceira Útil". Embora não seja um atributo componente do modelo de Wang e Strong (1996), considera-se que seja um aspecto muito importante a ser considerado para a determinação da qualidade da informação contábil. Levando em conta que esse atributo refere-se aos diferentes formatos pelos quais a informação deve ser disponibilizada para ser relevante e útil, entende-se que deveria ser uma característica a ser considerada, devendo portanto, ser incluída nas "Características Qualitativas da Informação Contábil-Financeira Útil".

\section{Conclusões}

Os resultados do estudo evidenciam similaridades, mas, ressaltam também diferenças significativas em relação aos aspectos, categorias e dimensões considerados para atribuir qualidade à informação nos dois campos do conhecimento. Constatou-se que, apesar de diferenças terminológicas, muitos atributos de qualidade da informação componentes das características qualitativas fundamentais possuem seus equivalentes 
na Ciência da Informação considerando-se a similaridade das definições dos aspectos que pretendem medir. Porém, atributos considerados importantes para a determinação da qualidade da informação na CI não são considerados nas "Características Qualitativas da Informação Contábil-Financeira Útil". Os resultados revelaram ainda que as dimensões, características e atributos de qualidade da informação utilizados como base nos estudos da Ciência da Informação são geralmente apresentados como simples listas de atributos corroborando os achados de Eppler e Wittig (2000). A despeito das tentativas de aplicação do modelo proposto por Wang e Strong (1996) e posteriores adaptações sugeridas por Huang, Lee e Wang (1999), não existe ainda na Ciência da Informação um framework definido para a determinação da qualidade da informação. Tal situação pode ser constatada pela diversidade de atributos e dimensões de qualidade consideradas em cada um dos estudos, não havendo nem mesmo um consenso em relação a atributos e dimensões de qualidade considerados em um mesmo contexto. Uma possível explicação é o fato de alguns atributos serem intrínsecos à definição do conceito de informação na CI diferentemente da Informação contábil que é definida em função do seu uso. Considerando a importância de um framework geral para a avaliação da qualidade da informação em contextos semelhantes, sugere-se a consolidação de um framework geral que pudesse servir como referência na análise da qualidade da informação na Ciência da informação e à Ciências Contábeis, uma revisão de seu framework para incorporar em sua estrutura conceitual atributos de qualidade da informação considerados pela CI que podem contribuir para a melhoria da qualidade das informações contábeis

\section{Referências}

ABIB, G. A qualidade da informação para a tomada de decisão sob a perspectiva do sensemaking: uma ampliação do campo. Ciência da Informação, v. 39, n. 3, p. 73-82, set./dez. 2010.

ALBUQUERQUE, A. dos S.; BASTOS, R. C.; LINO, M. R. de O. A qualidade da informação em portais do judiciário. Encontros Bibli: Revista Eletrônica de Biblioteconomia e Ciência da Informação, v. 14, n. 27, p. 115-134, 2009.

AMARAL, S. A. do; SOUSA, A. J. F. P. de. Qualidade da informação e intuição na tomada de decisão organizacional. Perspectivas em Ciência da Informação, v. 16, n. 1, p. 133-146, p.133-146, jan./mar. 2011.

AMORIM, A. D. G. A mediação da informação contábil sob a ótica da Ciência da Informação. 2007. 190 f. Tese (Doutorado em Ciência da Informação) - Escola de Comunicações e Artes, Universidade de São Paulo, São Paulo, 2007.

AROUCK, O. Atributos de qualidade da informação. 2011. 117 f. Dissertação (Mestrado em Ciência da Informação) - Faculdade de Ciência da Informação, Universidade de Brasilia, Brasília, 2011. 
AROUCK, O. Avaliação de sistemas de informação: revisão da literatura. Transinformação, v. 13, n. 1, p. 7-21, jan./jun. 2001.

ASSIS, J. de; MOURA, M. A. A qualidade da informação na Web: uma abordagem semiótica. Informação \& Informação, v. 16, n. 3, p. 96-117, maio 2012.

BARRETO, A. O destino da Ciência da Informação: entre o cristal e a chama. Datagramazero, Revista de Ciência da Informação, Rio de Janeiro, n. 0 , dez. 1999. Disponível em: <http://www.dgz.org.br/fev07/Art_01.htm>. Acesso em: 8 jun. 2010.

BUCKLAND, M. Information as thing. Journal of the American Society of Information Science, v. 42, n. 5, p. 351-360, 1991.

CALAZANS, A. T. S. Qualidade da informação: conceitos e aplicações. Transinformação, Campinas, v, 20, n. 1, p. 29-45, jan./abr. 2008.

CALAZANS, A. T. S. ; COSTA, S. M. de S. Modelo de avaliação da qualidade da informação estratégica bancária. Ciência da Informação, v. 38, n. 3, p. 21-39, set./dez. 2009.

CASANOVA, M. B. Information: the major element for change. In: WORMELL, I. (Ed.). Information quality: definitions and dimensions. London: Taylor Graham, 1990. p. 42-53.

COMITÊ DE PRONUNCIAMENTOS CONTÁBEIS (CPC). Pronunciamento conceitual básico (R1). Estrutura conceitual para elaboração e divulgação de relatório contábil-financeiro. Correlação às Normas Internacionais de Contabilidade - The Conceptual Framework for Financial Reporting (IASB - BV 2011 Blue Book). 2011. Disponível em: <http://www.cpc.org.br/pdf/cpc00_r1.pdf>. Acesso em: 29 jan. 2012

CONSELHO FEDERAL DE CONTABILIDADE (CFC). Resolução CFC 1.374/11. NBC TG estrutura conceitual - estrutura conceitual para elaboração e divulgação de relatório contábil-financeiro. Brasília, 2011. Disponível em: www.cfc.org.br/sisweb/sre/docs/RES 1374.doc. Acesso em: 18 mar.2012.

COMITÊ DE PRONUNCIAMENTOS CONTÁBEIS (CPC). CPC 00_R1: Estrutura conceitual para elaboração e divulgação de relatório contábilfinanceiro. Disponível em: <http://www.cpc.org.br/pdf/cpc00_r1.pdf. Acesso em: 5 fev.2012

DE SORDI, J. O. Análise da coesão entre seções de textos de documentos extensos a partir da aplicação conjunta das técnicas de análise de redes sociais e referências internas. Perspectivas em Ciência da Informação, v. 14, n. 1, p. 162-169, jan./abr. 2009.

DE SORDI, J. Administração da informação: fundamentos e práticas para uma nova gestão do conhecimento. São Paulo: Saraiva, 2008.

DE SORDI, J. O.; MEIRELES, M. A. Processo de gestão da informação em localidade com concentração de atividades da cadeia produtiva: 
extrapolando benefíci+os para o contexto do órgão gestor. Perspectivas em Ciência da Informação, v. 16, n. 4, p. 119-149, out./dez. 2011.

DE SORDI, J. O.; MEIRELES, M. A. Melhoria da qualidade da informação organizacional pela agregação de resumo: análise de softwares geradores de resumo. Ciência da Informação, v. 38, n. 1, p. 109-123, jan./abr. 2009.

DE SORDI, J. O.; MEIRELES, M. A.; GRIJO, R. N. Gestão da qualidade da informação no contexto das organizações: percepções a partir do experimento de análise da confiabilidade dos jornais eletrônicos. Perspectivas em Ciência da Informação, Belo Horizonte, v. 13, n. 2, p. 168-195, maio/ago. 2008

DIAS FILHO. J. M. A linguagem utilizada na evidenciação contábil: uma análise de sua compreensibilidade à luz da teoria da comunicação. Caderno de Estudos, São Paulo, Fundação Instituto de Pesquisas Contábeis, Atuariais e Financeiras (FIPECAFI), v. 13, n. 24, p. 38-49, jul./dez. 2000.

EPPLER, M. J.; WITTIG, D. Conceptualizing information quality: a review of information quality frameworks from the last ten years. In: CONFERENCE ON INFORMATION QUALITY. 2000. Proceedings... 2000. Disponível em: <http://mitiq.mit.edu/iciq/Documents/IQ\%20Conference\%202000/Papers CConceptIQaReviewofIQFramework.pdf>. Acesso em: 10 mar. 2011.

FUJINO, A.; JACOMINI, D. D. Produtos e serviços de informação na sociedade do conhecimento: da identificação ao uso. In: GIANNASIKAIMEN, M. J.; CARELLI, A. E. (Org.). Recursos informacionais para compartilhamento da informação: redesenhando acesso, disponibilidade e uso. Rio de Janeiro: E-Papers, 2007. p. 73-98.

GREEF, A. C.; FREITAS, M. do C. D. Fluxo enxuto de informação: um novo conceito. Perspectivas em Ciência da Informação, v. 17, n. 1, p. 37-55, jan./mar. 2012.

HENDRIKSEN, E. S.; BREDA, M. F. V. Teoria da contabilidade. 5. ed. São Paulo: Atlas, 1999.

HUANG, K. T.; LEE, Y.W.; WANG, R. Y. Quality information and knowledge. New York: Prentice-Hall, 1999.

INTERNATIONAL ACCOUNTING STANDARDS BOARD (IASB). Disponível em: <http://www.ifrs.org/About-us/IASB/Pages/Home.aspx>. Acesso em: 20 jun. 2013

IJIRI, Y. Theory of accounting measurement. Sarasota: American Accounting Association, 1975. (Studies in accounting research, 10).

IUDICÍBUS, S. de. Teoria da contabilidade. 7. ed. São Paulo: Atlas, 2006.

KNIGHT, S.; BURN, J. Developing a framework for assessing information quality on the World Wide Web. Informing Science Journal, v. 8, p. 159- 
172, 2005. Disponível em: <http://inform.nu/Articles/Vol8/v8p159172Knig.pdf >. Acesso em: 13 jul. 2011.

LE COADIC, Y.-F. A ciência da informação. Brasília: Briquet de Lemos Livros, 1996.

LOPES, A. B. A informação contábil e o mercado de capitais. São Paulo: Pioneira Thomson Learning, 2002.

LOPES, A. B.; MARTINS, E. Teoria da Contabilidade: uma nova abordagem. São Paulo: Atlas, 2005.

LOPES, I. L. Novos paradigmas para avaliação da qualidade da informação em saúde recuperada na Web. Ciência da Informação, Brasília, v. 33, n. 1, p. 81-90, jan./abril 2004.

NEHMY, R. M. Q. Leitura epistemológico-social da qualidade da informação. 1996. 118 f. Dissertação (Mestrado em Ciência da Informação) - Programa de Pós-Graduação em Ciência da Informação, Universidade Federal de Minas Gerais, Belo Horizonte, 1996.

NEHMY, R. M. Q.; PAIM, I. A desconstrução do conceito de "qualidade da informação". Ciência da Informação, Brasília, v. 27, n. 1, p. 36-45, jan./abr. 1998.

OLAISEN, J. Information quality factors and the cognitive authority of eletronic information. In: WORMELL, I. (Ed.). Information quality: definitions and dimensions. London: Taylor Graham, 1990. p. 84-91.

OLETO, R. R. Percepção da qualidade da informação. Ciência da Informação, v. 35, n. 1, p. 57-62, jan./abr. 2006.

PAIM, I.; NEHMY, R. M. Q.; GUIMARÃES, C. G. Problematização do conceito "Qualidade" da Informação. Perspectivas em Ciência da Informação, Belo Horizonte, v. 1, n. 1, p. 111-119, jan./jun. 1996.

SARACEVIC, T. Ciência da informação: origem, evolução e relações. Perspectivas em Ciência da Informação, Belo Horizonte, v.1, p. 41-62, jan./jun. 1996 citado por OLETO, R. R. Percepção da qualidade da informação. Ciência da Informação, v. 35, n. 1, p. 57-62, jan./abr. 2006.

SHANNON, C.; WEAVER, W. The mathematical theory of communication. Urbana: University of Illinois Press, 1949.

SMIT, J. W.; BARRETO, A. de A. Ciência da Informação: base conceitual para a formação profissional. In: VALENTIM, M. L. P. (Org). Formação do profissional da informação. São Paulo: Polis, 2002, p. 9-23

SPENDER, J. Gerenciando sistemas de conhecimento. In: FLEURY, M.; OLIVEIRA, JR., M. (Orgs.). Gestão estratégica do conhecimento: integrando aprendizagem, conhecimento e competências. São Paulo: Atlas, 2001. p. 27-49.

VALENTE, N. T. Z. Qualidade da informação contábil na perspectiva da Ciência da Informação. 2014. 323 f. Tese (Doutorado em Ciência da 
Informação) - Escola de Comunicações e Artes, Universidade de São Paulo, São Paulo, 2014.

VALENTE, N. T. Z.; FUJINO, A. Características qualitativas da informação contábil e os atributos e dimensões de qualidade na Ciência da Informação. In: CONGRESSO ANPCONT, 6., 2012, Florianópolis. Anais... Florianópolis: ANPCONT, 2012.

WANG, R. Y.; STRONG, D. M. Beyond accuracy: what data quality means to data consumers. Journal of Management Information Systems, v. 12, $\mathrm{n}$. 4, p. 5-33, 1996.

WORMELL, I. (Ed.). Information quality: definitions and dimention. London: Taylor Graham, 1990. 